\title{
Una Nota a Fray Luis de León
}

por Luis Jaime Cisneros

A Jorge Puccinelli.

La unidad es cosa que atrae fuertemente a Fray Luis. Ahí están, para probarlo, los temas del amor; el amor es camino de unidad: "Porque el amor, como platicabais ahora, Juliano y Sabino, es' unidad, o todo su oficio es hacer unidad; y cuanto es mayor y mejor la unidad, tanto es mayor y más excelente el amor; por donde cuanto por más particulares maneras fueren uno mismo dos entre sí, tanto sin duda ninguna se tendrán más amor" (1). Por el camino de la unidad de la lengua, nos acomodaremos para plantear, respecto de Fray Luis, la tesis de la tradición española. Ella nos permitirá ver al agustino como un hito que marca el paso de Garcilaso a Sani Juan, con la cumplida claridad y el fuerte colorido de Berceo y el tono filosófico elevado de Manrique. Claro que la probanza exigiría una larga y erudita digresión, acá fuera de propósito. La evitaremos, en cuanto sea compatible con nuestra intención, poniendo algunos ejemplos.

Se ha hablado durante largo tiempo de la tradición italiana. González Palencia habla de cómo al traducir a clásicos e italianos, antes que el modo italiano prefería Fray Luis los modos de la tradición castellana, con cara a Castillejo (2). Es verdad. Dámaso Alonso ha hecho en fino análisis el límite de las comunicaciones poéticas con Garcilaso. (3). También es cierto. Pero hay algo más que eso; hay una fuerte corriente tradicional castellana inadvertida, que viene de la edad media española. Por eso no yerran quienes piensan que el poeta no desdeña las glosas de cantarcillos' populares, tan del gusto de la escuela tradicionalista. En Fray Luis coincidían muchas corrientes e influencias; a éstas quiere seguramente referirse Alonso cuando habla de que el ita- 
lianismo de Fray Luis no había de pasar de lo más externo, pues en lo interior estaría suplantado por su castellanismo y por otras influencias. $Y$ esta tradición medieval es cierta; como que se cumple, en lo que va estudiàdo del poeta, en aquella Profecía, del Tajo que Alonso analizó con maestría en su ciclo memorable de San Marcos (4). Nunca como ahora hay que repetir que en Fray! Luis no se interrumpe la tradición nacional, pues está bien enraizado en el terruño, apegado al ruralismo español.

"Complejidad de raíces y complejidad de eficacia", hay en Fray I.uis. No se ha entendido hasta la saciedad este parecer de Dámaso Alonso. Porque, ¿en qué forma el poeta altera nuestro mundo moral? Hay que ahondar, para ello, en el ideal lingüístico de Fray Luis; hay que calar en De las nombres de Cristo, abra en prosa sí, pero obra, si se mira bien, en prosa poética, que encierra buena parte, por no decir la mayor, de los secretos estilísticos del agustino. Prosa poética si nos atenemos más al sentido que al lenguaje, pero poesía. La historia es larga; la historia viene de las primeras controversias sobre el ideal de la lengua: el más inmediato, Fernando de Herrera; más atrási Ambrosío de Morales; más allá, casi en los albores del gran mundo español, Antonio de Nebrija.

No hay libro más conllevable con nuestro propósito que el citado De los nombres de Cirsto. "En la' forma del decir, la razón pide que las palabras y las cosas que se dicen por ellas sean conformes, y que lo humilde se diga con llaneza, yelo grande con estilo más levantado, y lo grave con palabrasiy con figuraseclualesrconvienen" (5). Fray Luis no habla "desatadamente y sin orden": "porque pongo en las palabras concierto y las escojo y les doy su lugar". Es el orden y concierto de que habla, el Inca Garcilaso. El bien hablar es para él "negocio de particular juicio, ansí en lo que se dice como en la manera como se dice; y negocio que de las palabras que todos hablan elige las que convienen y mira el sonido dellas, y aun cuenta a veces las letras y las pesa y las mide y las compone, para que no solamente digan con claridad lo que se pretende decir, sino también con armonía y dulzura" (6). La unidad, la armonía de la lengua es tema que nutre su posición estética. Orden y concierto, dulzura y armonía vivirán, y ya veremos en qué medida, en su obra. Unidad de la lengua, que se sirve de todas las perspectivas. No habrá sino que recorrer la obra de Fray Luis para advertirlo. Recorrerla con el oído atento. Salir de Berceo para quedarse largo rato en Manrique. Porque esta influencia de Manrique, unas veces lejana como un presentimiento, viva otras como una presencia 
"fiera, airada", merece comentario. De Manrique nos hemos ocupado muy poco en lo que va de siglo, repitiendo pasados errores. Hora se rá de darle mejor sitio y más noble perspectiva, aventurándonos por el camino que acaba de iniciar con tanta responsabilidad y tanto celo Pedro Salinas. A Manrique lo encontramos, y no creo imprudente la afirmación, en Cervantes con más frecuencia, con más insistencia de lo que fuere dado sospechar.

Sí, es probable que en Manrique haya bebido Fray Luis su idea del amor. Y de la idea de la muerte que el poeta del cuatrocientos recoge, el poeta, de la edad de oro extraerá la idea de la soledad, camino al puerto seguro de su unión con Dios. Pero como se dan dos ideas en Manrique del amor, el agustino desechará la del amor cortesano y buscará aquella otra que haciendo al amor camino indispensable de la muerte, crea al mismo tiempo la idea ascensional del amor como camino de Dios. El camino unitivo del amor es a la larga la voz que obliga al poeta a huir de la ciudad y hallar en el campo sosiego, y con el sosiego la soledad. No es él frente al mundo; es él frente a sí mismo, exponiendo ante el mundo su desolada soledad y una muy clara desnudez. Es el amor a la soledad y "el aborrecimiento hacia la aldea de Tibulo los que lo animan", según advierte G. Palencia, (7), apoyándose en la elegía que comienza:

Al campo va miblior, y va a la aldeatras el hombre que morada un punto soloverson hiciera en la ciudad, maldito sea.

Así se ha podido observar que su paisaje preferido es el campestre, digamos mejor rural. Por eso la más lograda exposición poética en su libro De los nombres se da en el análisis de la voz pastor. La ciudad es cosa que,vive fuera de sus versos; apenas la ve él como la "errada muchedumbre". La muchedumbre, como no tiene perfil ni personalidad, es también soledad; busca él para aludirla, entonces, aquel ángulo en que la muchedumbre se conlleva con "su" manera de ser. La ciudad le parece "tinieblas, suplicio, alboroto", frente al campo, que se le aparece como una "luz purísima en sosiego eterno".

Pero vengamos a esperar a Fray Luis en el pórtico medieval de Berceo (8):

Yo maestro de Goncalvo de Berceo nomnado iendo en romeria caeci en un prado 
verde e bien sencido, de flores bien poblado, logar cobdiciaduero para omne cansado.

5 Daban olor soveio las flores bien olientes, refrescavan en omne las caras e las mientes, manavan cada canto fuentes claras corrientes, en verano bien frias, en yvierno calientes:

10 Avie hi grand abondo de buenas arboledas, milgranos e figueras, peros e mazanędas, e muchas otras fructas de diversas monedas, mas non avie ningunas podridas nin azedas.

15 La verdura del prado, la olor de las flores, la sombra de los árbores de temprados sabores refrescáronme todo, e perdí los sudores: podrie vevir el omne con aquellos olores.

Nunqua trové en sieglo logar tan deleitoso, nin sombra tan temprada, ni olor tan sabroso. Descargué mi ropiella por iazer mas vicioso,

20 poseme a la sombra de un árbor fermoso.

Y oigamos al pibetalcastellano, den sueđda XXV:

Mi trabre Pyccinelli Converson

un poco hacia la tarde se inclinaba y libre ya del grave ardor pasado las fuerzas recogía.

5 c'xando sin entender quién me llevaba a la entrada me hallé de un verde prado de flores mil sembrado, obra dó se estremó naturaleza. El suave olor, la no vista belleza

10 me convidó a poner allí mi asiento.

27 Cercada de frescura más clara que el cristal hallé una fuente en un lugar secreto y deleitoso; 
Pasemos por alto lo del modelo petrarquista. Aquí nace el entronque. No vamos a detenernos en él, que sería perdernos en especulaciones de orden científico, sujetas a rigurosos métodos estilísticos, que escapan hoy a mi intención. Recordemos apenas que aquí nace la voz. Si es verdad que entre los libros de Fray Luis nunca se halló un ejemplar de Dante y que la crítica opina, por eso, que no conoció el agustino al poeta de Florencia; y si es vendad que frente a esta tesis la crítica argentina sostiene, por vías que permanecen aún en el terreno de la conjetura (9), que pudo conocerlo, la verdad parece ser aquélla; y lo que se da bebido en Dante estaría, entonces, bebido en Berceo, y si afinamos bien el oído, en Juan de Mena.

Un no rompido sueño,

un día puro, alegre, libre quiero;

no quiero ver el ceño

vanamente severo

30 de quien la sangre ensalza o el dinero.

La alegría sólo puede darse en la libertad, y para sentirse libre hay que llegar a serlo por el camino de la alegría, que nace en la pureza; y eso no es de la tierra que es vagoroso sueño. El poeta quiere, entonces, que el sueño se prolongue:

Un no rompido sueño,

un día puro, alegre, libre quiero.

El dinero y la sangre, señalados como errores pasajeros de la vida por la edad media española, acosan al poeta. Pero él no quiere verlos:

ro quiero ver el ceño

venamente severo

de quien la sangre ensalza o el dinero.

Y si él busca un descansado sueño, es porque recuerda sin duda aquel prado de Berceo, que antes recordamos:

Despiértenme las aves

con su cantar suave no aprendido, 
no los cuidados graves

de que es siempre seguido

35 quien al ajeno arbitrio está atenido.

Recordemos a Berceo nuevamente. Yendo en romería, acaeció en un prado bien poblado de flores, lugar ambicionado por el hombre que busca y quiere descansar:

Yaziendo a la sombra perdí todos cuidados, odí sonos de aves dulces e dolulados:

Las aves que organan entre essos fructales, que an las dulzes vozes, dicen cantos leales,

Quiero dexar con tanto las aves cantadores, las sombras e las aguas, las devant dichas flores.

¿No son éstas, acaso, las aves con que espera Fray Luis encontrarse al despertar? Esta Oda a la vida retirada, si bebida en Horacio, parece recoger casi toda la técnica del poeta benedictino:
A mí una pobrecilla
mesa de amable pazcien abastadaerso"
me baste, y la bajilla,
de fino oro labrada
75 sea de quien la mar no teme airada.

Y mientras miserable

mente se están los otros abrasando

en sed insaciable

del no durable mando,

80 tendido yo a la sombra esté cantando.

$\mathrm{Si}$, es la misma actitud del poeta riojano que halla el lugar "cobdiciadero" y se acuesta a la sombra de un "arbor fermoso". La modestía horaciana de Fray Luis, el amor a la soledad, se confunde con aquel recato de quien se llegó al monasterio de San Millán, allá en días muy viejos, trayéndose entre papeles un nuevo mester de poesía. 
Dice el poeta en su dedicatoria a don Pedro Portocarrero: (10"... entre las ocupaciones de mis estudios en mi mocedad, y casi en mi niñez, se me cayeron como de entre las manos esias obrecillas, a las cuales me apliqué más por inclinación de mi estrella que por mi juicio - voluntad". De las manos se nos caen éstas también. Mas no debió de ser el suyo gesto de hombre que desdeña el fruto, sino de consciente sembrador: él mismo parece atestiguarlo:

Del monte en la ladera

por mi mano plantado tengo un huerto, que con la primavera de bella flor cubierto

45 ya muestra en esperanza el fruto cierto.

La vida es dura, y en ella vive prisionero el cuerpo. Muro, cerco y prisión será para Fray Luis; por eso en su Oda a Felipa Ruiz (VII) clama por la más alta rueda de Juan de Mena:

¿Cuándo será que pueda

libre de esta prisión volar al cielo.

Felipe, y en la rueda

que huye más del suelo,

5 contemplar laiverdad pura sihevèlo?tras

¿Qué verdad quiere contemplar el poeta de Salamanca? No, no la verdad pura del cielo; muy ciega ha estado la crítica que quiso entenderlo así: es el propio Fray Luis quien lo declara:

Allí a mi vida junto

en luz resplandeciente convertido

veré distinto $\mathrm{y}$ junto,

lo que es, y lo que ha sido,

10 y su principio propio y escondido.

El secreto escondido de las cosas, la verdadera historia, se abrirán silenciosamente a los oios escrutadores del poeta: es el poeta mirando hacia la tierra:

Entonces veré cómo

el divino poder echó el cimiento

13 tan a nivel y plomo, 
I.a oposición será en él técnica preferida. Cuando habla desde la tierra, busca el cielo; pero cuando esté en el ansiado puerto, entonces se dará a ver lo que ha pasado, como Manrique.

He aquí el centro. Recordemos la tierra castellana. Se ha dicho que Fray Luis juntó en una sola voz la diversidad y el tiempo. "Quien lo gusta en lo que dice y no penetra en el ambiente que envuelve sus poemas, en lo que sugiere, en lo que oculta, afirma Marasso, pierde parte del encanto de las asociaciones y acercamientos con cosas distintas a remotas que une la magia de su verso, que ilumina con un vocablo, con el corte de una frase". Sus versos reflejan el campo con el realismo de las cosas ordinarias, pero con un cierto halo de sublimidad: Ya advierte González Palencia que es poeta de descripciones espontáneas, difícil de imitar; por eso cuando busca imitar a los modelos antiguos o los traduce lo hace de tal modo que "mete en ellos, como dice Alonso, algo de su propio espíritu catsellano, de un espíritu castizo, prolongación del de la Edad Media" (11).

Le preocupan a Fray Luis la inseguridad de la vida y la seguridad del cielo: él entiende a la poesía como nexo entre tierra y cielo, como obligada ruta del hombre que va a su Salvador; olgámoslo de él mismo: (12): "sin duda la inspiró Dios (la poesía) en los ánimos de los hombres para con el mgvimiento y espíritu della levantarlos al cielo, de donde ella procede; porque la poesia no es sino una comunicación del aliento celestial y divino y assi, en los profetas cuasi todos, assi los que fueron movidos verdaderamente por Dios, como los que incitados por otras causas sobrehumanas hablaron, el mismo espíritu que los despertava y levantava a ver lo que los otros hombres no vían, les ordenaba y componía y como metrificada en la voca las palabras, con numero y consonancia devida, para, que hablassen por más subida manera que las otras gentes hablavan, y para que el estilo del dezir se assemejasee al sentir, y las palabras y las cosas fuessen conformes". Por todos lados, como vemos, la preocupación por el orden y el concierto de las cosas, por el orden y concierto de las almas; por todos lados, unidad.

Huye del ruido de la ciudad, que corresponde a la insegura vida, se aleja de la tama pregonera: todo eso es tempestad, viento malsano; él busca el campo, el río, el "secreto seguro deleitoso". Frente al torbellino de la ciudad tempestuosa, el "almo reposo" donde podrá com. partir el silencio en legítima propiedad. 
Dígalo con mejor elocuencia su verso en la Noche serena:

¡Ay! despertad mortales;

mirad con atención en vuestro daño;

¿las almas inmortales

30 podrán vivir de sombra y solo engaño?

!Ay! levantad los ojos

a aquesta celestial eterna esfera,

burlaréis los antojos

de aquesa lisonjera

vida, con cuanto tema y cuanto espera.

¿Es más que un breve punto

el bajo y torpe suelo, comparado

con este gran trasunto,

do vive mejorado

40 lo que es, lo que será, lo que ha pasado?

Sino que la evasión se impone siempre en él. La tierra le recuerda la clara luz del cielo; el bien ansiado de éste lo lleva a reparar en los vanos cuidados, del cuerpo, de la tierra. Menosprecio de la ciudad, que es como el cuerpo de la terra; y alabanza de la aldea, que es el alma. Menosprecio del cuerpo, equé es como la tierra en que se asientan las virtudes; y alabanza del cielo, do las virtudes vuelan con el alma. Y en buena cuenta, soledad. Lo que priva en el poeta es siempre la idea del apartamiento, porque, al fin y al cabo, y lo veremos en su sitio, por la vía del apartamiento ilegará a la zona poblada del amor de Dios. Es un caso típico de la mística española, si tenemos por místico a Fray Luis en lo que tiene de impulso por elevarse a la unión con Dios, como plensa Dámaso Alonso (13). No obstante, digamos de paso que los hallazgos del padre Muñoz Sendino obligan a revisar esta posición del catedrático español.

Pero soledad la suya muy sola y desamparada. Porque no solamente es la soledad del campo; es la soledad de su alma, luz, envuelta en la ancha soledad de la tierra castellana, oscura. Su honda soledad sonora. Huye al prado para evitar el ruido ciudadano, porque no hay atractivo para él en la ciudad; pero en el valle, su soledad acrece, pues con estar presente en torno de sus cosas, alejada del mundo y del recuerdo, 
hay entre prado y monte barrera que el poeta tiene que salvar. Veámoslo, sin ir más lejos, en su oda Al apartamiento:

¡Oh ya seguro puerto

de mi tan luengo errorl joh deseado

para reparo cierto

del grave mal pasado,

5 reposo alegre, dulce, descansado.

No hagamos hincapié en la disposición da los adjetivos, que buscan su ritmo y su entonación a través del hipérbaton. Vayamos solamente a la idea. Por fin se ha liberado el poeta de los errores de la vida y alcanza dulce y alegre reposo en el deseado apartamiento. No hay amigos en torno, no hay voces periuras, no hay testigos. Entonces, puede dar el poeta rienda a su voz: es el momento en que se incorporan al paisaje, para compartir la soledad del hombre, pero para servirle, de camino de perfección, la sierra, el monte:

Sierra que vas al cielo

altísima, y que gozas del sosiego

que no conoce el suelo,

a donde el vulgo ciego

15 ama el morir ardiendo en yivo fuego; (14)

Recíbeme en tú cumbre, inelli Converso"

recíbeme que huyo perseguido

la errada muchedumbre,

el trabajo perdido.

20 la falsa paz, el mal no merecijo.

La soledad es propicia a la confesión; ha llegado al campo el poeta sobrellevando hartas fatigas, no merecidos males y dolores. La ciudad es asiento de la errada y errante muchedumbre. El quiere salirse del error, de su tan luengo error. Y como el aire de la ciudad de que huye es fiero, airado, pide al monte, cual sì pidiera al cielo, un más sereno aire, porque adivina que ahí donde la divinad tenga morada reinarán los vientos plácidos que cantan los latinos:

Y do está más sereno

el aire me coloca, mientras curo 
los daños del veneno

que bebí mal seguro,

25 mientras el mancillado pecho apuro.

Mientras que poco a poco

borro de la memoria cuanto impreso

dejó allí el vivir loco

por todo su proceso

30 vario entre gozo vano, y casi avieso.

En tí, casi desnudo

de este corporal velo, y de la asida

costumbre roto el nudo,

traspasaré la vida

35 en gozo, en paz, en luz no corrompida.

iAy، otra vez y ciento

otras, seguro puerto deseadol

no me falte tu asiento.

y falte cuanto amado,

65 cuando del ciego, error es codiciado.

\section{Biblioteca de Letras}

Quizá cupiera decir aquí que estamos frente a lo que podríamos llamar los albores de la corriente iluminativa. Como la vida es cárcel y cerco y muro, y como sobrellevarla implica arrastrar duelos, fatigas, lloros y crudezas, mal merecidos males, el poeta, para salir de esa cárcel en que se siente encerrado, debe traspasarla, Un traspasar, que supone quebrar los muros, el cerco férreo y duro del cuerpo, para penetrar en el alma sosegada. Desde esta oda, el verbo comienza a ser frecuente en el vocabulario del poeta. Veamos cómo en su Morada del cielo se nutre del sentido de transmisión etérea que cuadra a la música:

Toca el rabel sonoro,

y el inmortal dulzor al alma pasa,

con que envilece el oro,

$y$ ardiendo se traspasa

30 y lanza en aquel bien libre de tasa. 
IOh son, oh voz! siquiera

pequeña parte alguna desciendiese

en mi sentido, y fuera

de sí el alma pusiese

35 y toda en tí, joh amor, la convirtiese!

¿No es ésta, acaso, la vía del amor que cobrará sentido en San Juan, pero cuyas raíces cabe empezar a estudiar en Fray Luis, sobre todo frente a las últimas revelaciones de la versión poética del Cantar?

Sobre la Vida retirada, la Oda a Salinas y la Profecía cel Tajo, se ha dicho mucho y bien recientemente en el Perú. Vamos a analizar nosotros la oda $A$ la ascensión, que se conlleva con estos propósitos de buscar las claras raíces de la tradición poética castellana medieval. Elsta composición está, por otra parte, entre las que más a propósito ofrece Fray Luis para rastrear, en nuestro sentir, la influencia lejana de Manrique. Esta influencia, justo es decirlo, fué anotada a vuelapluma por Vossler hace algunos años y no ha despertado, por lo menos yo no tengo noticia, interés alguno entre los críticos (15):

$Y$ dejas, Pastor santo,

tu grey en este valle hondo, escuro

con soledad y llanto,

y tú rompiendo el puro

5 aire, te vas al inmortal seguro? onverso"

¿Los antes bienhadados,

y los agora tristes y afligidos,

a tus pechos criados,

de tí desposeídos,

10 a dó convertirán ya sus sentidos?

¿Qué mirarán los ojos

que vieron de tu rostro la hermosura,

que no les sea enojos?

quien oyó tu dulzura,

15 ¿qué no tendrá por sordo y desventura??

¿Aqueste mar turbado

quién le pondrá ya freno? ¿quién concierto 
al viento fiero, airado? estando tú encubierto,

20 ¿qué norte guiará la nave al puerto?

$\lceil$ Ay! nube envidiosa

aun de este breve gozo, ¿qué te quejas?

¿do vuelas presurosa?

¡¡cuán rica tú te alejas!

25 jcuán pobres y cuán ciegos, ay, nos dejas!

¿Verdad que ya estamos como repitiendo el tema de las Coplas a la muerte del maestre de Santiago? Pero, todavía hay más. La lira de Fray Luis, de versos quebrados, en los que aprieta el poeta todo el sentido que deba informar a los endecasílabos, tiene un símil perfecto en la técnica del arte menor de Manrique: versos de once y siete sílabas en La Morada del Cielo; versos de ocho y de cuatro en el hijo de don Rodrigo. Y no sólo eso; vayamos a la intención, a los secretos: El Paš tor abandona la tierra, la insegura tierra; va de la inseguridad de esto mundo a la seguridad del cielo, y la ausencia acrece la distancia entre el cuerpo y su salvador. Ved cómo crece esa distancia:

\section{Y dejas, Pastor santo. \\ tu grey en este valle hondo, escuro \\ con soledad yllanto,}

Es lo que repetimos todos los días: el valle de lágrimas. Al subir al cielo el Salvador, ha crecido su figura ante quienes habían compiartido su presencia; se han quedado así hundidos en la tierra. Y como él era la luz, se ha hecho en torno la oscuridad. Y hay un hueco en nosotros mismos, porque la luz nos ha quitado la perspectiva. Sin luz no vemos. No ver es una manera de estar solo. Hemos quedado en soledad. Y como esa soledad se deriva de nuestro desamparo; y como es soledad venida de adehala, nosotros, que somos el rebaño, clamamos por el Pastor. Pero el pastor no viene, y lloramos. ¿Recordáis la soledad de María? Era soledad con llanto, porque era un duelo de pérdida total. ¿Recordáis la soledad de Jimena en el Poema del Cid? Era la soledad compartida con "el llorar de los ojos", porque se había desprendido como la uña de la carne". Soledad acompañada de lágrimas, que es la más amarga, porque es la soledad ensimismada. 
Pero el Pastor, al ascender al cielo, asume sus cualidades divinas e inmutables, hace caso omiso de este desasosiego del rebaño, y hay como un halo de luz que cruza el aire en dirección al cielo:

y tú rompiendo el puro

aire, te vas al inmortal seguro?

La inseguridad del cuerpo, la inseguridad de la vida, tiene felizmente término. "Romeos de la vida" somos como quería Berceo. El seguro puerto no conoce la muerte.

Jorge Manrique, siguiendo la tradición latina del UBI SUNT, para recordar lo presente vuelve la mirada hacia el pasado. Y así, Fray Luis ¿Qué será de, aquellos que, dichosos ayer por haber compartido la presencia del Pastor, se sienten sin rumbo? La alegría de ayer es el dolor y la desorientación de hoy:

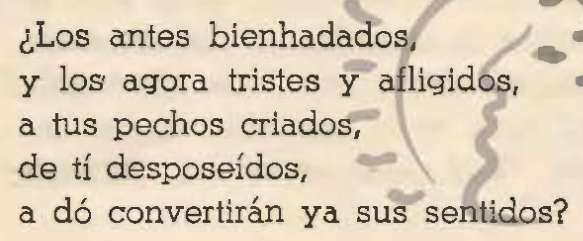

El Pastor era el quiblintrabaclos sentidos; ilos sentidos todos del rebaño estaban en él. "Yo El gera la dichá y la bonanzay el hado. Y ellos, los bienhadados. Pero la oscuridad y el llanto traen con ellos la tristeza y la afiicción; el rebaño, privado del pastor, necesita un nuevo rumbo, necesita "convertir" sus sentidos, darles otra orientación y fuerza nueva. Es reflexión del alma, que se sale del cuerpo y tiene a su merced más honda perspectiva. Es reflexión que se eleva por sobre todas las miserables cosas y comprende la derrota. Porque, criados a la vera del pastor, conocieron todos sin saberlo la belleza y la dulzura y tuvieron prontos los oídos a las músicas y sus ojos sólo conocieron la calma, la claridad del mar.

Se preguntaba Manrique:

85 Decidme: La hermosura, (VII) la gentil frecura y tez de la cara, 
la color e la blancura, quando viene la vejez,

90 ¿cual se para?

Los placeres e dulcores' (XII) desta vida trabajada

35 que tenomos, no son sino corredores, e la muerte, la celada en que caemos.

Non mirando a nuestro daño

140 corremos a rienda suelta sin parar;

desque vemos el engaño e queremos dar la vuelta, non hay lugar.

$145 \mathrm{Si}$ fuesse en nuestro poder hazer la cara hermosa corporal, come podemos hazer el alma tan gloribsa,oteca de Letras

150 angelical, "Jorge Puccinelli Converson ¡qué diligencia tan viva, toujéramos toda hora, e tarı presta. en componer la cativa,

155 dexándonos la señora descompuesta!

La veiez es también la soledad del alma que siente el peso de los pecados de su cuerpo. Lo mismo ocurrirá en Fray Luis. Como la presencia del Pastor transmitía al ambiente las naturales cualidades de la divinidad, no había espacio sino para la hermosura. Porque entonces la tierra era el cielo; pero esta ausencia del Pastor (y podríamos ya decir esta ausencia del Amado) deja a la tierra convertida en tierra y devuelal cielo sus perdidos y consabidos atributos. La hermosura partirá con el pastor, la vejez comenzará a cercar el alma: 
¿Qué mirarán los ojos que vieron de tu rostro la hermosura, que no les sea enojos? quien oyó tu dulzura ¿qué no tendrá por sordo y desventura?

Ceguera y sordera, para acentuar la soledad y el llanto. Sordera y ceguera que si se rompen, por obra de la vitalidad del cuerpo, dan desventura y fealdad, para honda pena del alma.

$Y$ en el paisaje, el mar. Recordemos aún al poeta del cuatrocientos:

Nuestras vidas son los ríos que van a dar en la mar, que es el morir;

La vida del rebaño, que transcurría en apacible mar mientras estaba al cuidado de pastor, sufre los embates de la furia y de la tempestad, que son el desgobierno del mar. El río del hombre pierde el cauce y ya no sabe el camino del seguro puerto:

¿Aqueste mar turbado

quién le pondrá ya freno? ¿Quién concierto

al viento fiero, airado? Ca de Letras estando tú encubierto,ccinelli Converso"

¿qué norte guiará la nave al puerto?

Hondo poeta Fray Luis. Nunca tan fuertes en él las raíces castellanas, pero nunca tan claramente expuestas. Está en el centro de ese camino que buscando su más puro origen en Berceo, se nutre de Manrique y Garcilaso para volcarse, todo luz, en el mundo poético de San Juan.

(1) De los nombres de Cristo, II (cito por ed. Federico de Onís, Clásicos Castellanos, 3 vols.). Para las citas poéticas utilizó, a falta de la meritísima edición de Llobera (Madrid, 1932) la del padre Merino, Obras del P. Mtro. Fr. Luis de León, 4 vols. Madrid, 1885. Las de Manrique se harán por ed. Augusto Cortina, IClásicos Castellanos, XCIV). 
(2) Fray Luis de León en la poesía castellana, (En Historias y Leyendas, Madrid, 1942. 177-21.3).

(3) Notas sobre Fray Luis de León y la poesía renacentista. (En Ensasayos de poesía, española, Madrid, 1944. 151-174).

(4) Forma y espiritu en la poesía de Fray Luis de León, (En Poesía y; novela de España. Universidad de San Marcos. Lima, 1948. 27 $-45)$.

(5) De los nombres de Cristo, Libro III. Dedicatoria, 8-9.

(6) Ibíd., 10.

(7) A. González Palencia, op. cit., 189.

(8) Ciio por ed. Solalinde, (Clásicos_Castellanos, XLIV).

(9) Fray Luis de Leín, poesłas. 'Clásicos Estrada, Buenos Aires, 1946. Prólogo y notas de Arturo Marasso; 11-38. pág. 25.

(10) Merino, op. cit. Brol. IV 29leca de Letras

(11) Ensayos, 153. "Masadelanten amplíaralonso"el tema, 163 y ss.

(12) De los nombres de Cristo, Lib II. "Monte".

(13) op. cit., 168. Respecto del misticismo, cabe señalar con Alonso que cuando a él llega, lo hace Fray Luis por la vía intelectual.

(14) Repárese en este verso cuando se estudie la llama de amor vivo en en San Juan.

(15) Karl Vossler, La soledad en la poesía española. Revista de Occidente, Madrid, 1941. pág. 170. 